\title{
Effect of classroom-based physical activity interventions on academic and physical activity outcomes: a systematic review and meta-analysis
}

Amanda Watson, Anna Timperio, Helen Brown, Keren Best and Kylie D. Hesketh*

\begin{abstract}
Background: Physical activity is associated with many physical and mental health benefits, however many children do not meet the national physical activity guidelines. While schools provide an ideal setting to promote children's physical activity, adding physical activity to the school day can be difficult given time constraints often imposed by competing key learning areas. Classroom-based physical activity may provide an opportunity to increase school-based physical activity while concurrently improving academic-related outcomes. The primary aim of this systematic review and meta-analysis was to evaluate the impact of classroom-based physical activity interventions on academic-related outcomes. A secondary aim was to evaluate the impact of these lessons on physical activity levels over the study duration.
\end{abstract}

Methods: A systematic search of electronic databases (PubMed, ERIC, SPORTDiscus, PsycINFO) was performed in January 2016 and updated in January 2017. Studies that investigated the association between classroom-based physical activity interventions and academic-related outcomes in primary (elementary) school-aged children were included. Meta-analyses were conducted in Review Manager, with effect sizes calculated separately for each outcome assessed.

Results: Thirty-nine articles met the inclusion criteria for the review, and 16 provided sufficient data and appropriate design for inclusion in the meta-analyses. Studies investigated a range of academic-related outcomes including classroom behaviour (e.g. on-task behaviour), cognitive functions (e.g. executive function), and academic achievement (e.g. standardised test scores). Results of the meta-analyses showed classroom-based physical activity had a positive effect on improving on-task and reducing off-task classroom behaviour (standardised mean difference $=0.60$ (95\% Cl: $0.20,1.00)$ ), and led to improvements in academic achievement when a progress monitoring tool was used (standardised mean difference $=1.03$ (95\% Cl: 0.22,1.84)). However, no effect was found for cognitive functions (standardised mean difference $=0.33(95 \% \mathrm{Cl}:-0.11,0.77)$ ) or physical activity (standardised mean difference $=0.40(95 \% \mathrm{Cl}:-1.15,0.95)$ ).

Conclusions: Results suggest classroom-based physical activity may have a positive impact on academic-related outcomes. However, it is not possible to draw definitive conclusions due to the level of heterogeneity in intervention components and academic-related outcomes assessed. Future studies should consider the intervention period when selecting academic-related outcome measures, and use an objective measure of physical activity to determine intervention fidelity and effects on overall physical activity levels.

Keywords: Classroom, Physical activity, Academic performance, Children, Schools, Intervention, Systematic review, Meta-analysis

\footnotetext{
* Correspondence: kylie.hesketh@deakin.edu.au

Institute for Physical Activity and Nutrition (IPAN), School of Exercise and

Nutrition Science, Deakin University, Geelong, Australia
} 


\section{Background}

Multiple physical and mental health benefits can be attained when children participate in the recommended 60 min per day of moderate- to vigorous-intensity physical activity [1, 2]. Despite these benefits, population based-studies have reported that over $50 \%$ of children in Australia and internationally are not meeting recommendations [3-6]. Schools are considered ideal settings for the promotion of children's physical activity. There are multiple opportunities for children to be physically active over the course of the school week, including during break times, sport, Physical Education class and active travel to and from school. Studies have shown interventions targeting these discrete periods may be effective in increasing children's physical activity levels $[7,8]$, with the potential to contribute to up to $50 \%$ of the physical activity required to meet physical activity guidelines [9]. However, with limited time available during these discrete periods, additional opportunities may be required in order for children to achieve the recommended levels of physical activity. Classroom-based physical activity provides another way for children to be active at school. This involves classroom teachers incorporating physical activity into class time through either integrating physical activity into lessons (physically active lessons), or adding short bursts of physical activity, either with curriculum content (curriculum focused active breaks) or without (active breaks).

There is increasing interest from researchers and education professionals about the potential for classroom-based physical activity to positively impact academic-related outcomes, including classroom behaviour, cognitive function and academic achievement. While some teachers express concern that classroombased physical activity may have an adverse effect on on-task classroom behaviour [10], emerging evidence from systematic reviews and meta-analyses suggest that overall physical activity may have a small positive effect on on-task classroom behaviour [11-17]. There is less evidence on classroom-based physical activity.

Narrative reviews [18-20], one systematic review [21] and two meta-analyses $[22,23]$ have explored the impact of classroom-based physical activity interventions on academic-related outcomes. However, these were narrow in scope, included few studies, and combined findings among primary and secondary school students, which may be problematic due to the difference in education settings.

A systematic review of 11 studies concluded that physically active lessons may have a positive effect, or no effect on academic-related outcomes [21]. However, that study did not consider other forms of classroombased physical activity (e.g. active breaks), combined findings among primary and secondary school students, and did not include a meta-analysis [21].

A meta-analysis of four intervention studies found that classroom-based physical activity had a positive effect on academic-related outcomes $(\mathrm{M}=0.67 ; 95 \% \mathrm{CI}: 0.26,1.09)$ [23]. Similar results were reported in a meta-analysis of 24 intervention studies investigating the association between different types of physical activity (e.g., during recess or lunch vs. active breaks vs. physically active lessons) and school engagement (behaviour at home and at school, and emotions, e.g. lesson enjoyment) [22]. In that meta-analysis, overall results showed physical activity had a significant positive effect on school engagement $(\mathrm{d}=0.28 ; 95 \% \mathrm{CI}: 0.12,0.46)$ [22]. When broken down into type of physical activity, active breaks ( $n=4$ studies) appeared to be the most effective type of intervention for improving school engagement ( $d=0.55 ; 95 \%$ CI:0.02,1.06), compared with recess or lunch time physical activity ( $n=3$ studies; $\mathrm{d}=0.26 ; 95 \% \mathrm{CI}:-0.19,0.73)$ and physically active lessons $(n=5$ studies; $\mathrm{d}=0.22 ; 95 \% \mathrm{CI}$ : $-0.21,0.66)$ [22]. However, results from those metaanalyses are limited by the small number of included studies [22, 23], the narrow range of potential academic-related outcomes assessed, the combination of findings among primary and secondary school students [22], and their recency [23].

The current paper aims to expand on findings from these reviews by conducting a systematic review and meta-analyses of the evidence of effect of classroombased physical activity interventions (active breaks, curriculum-focused active breaks and physically active lessons) on a broad range of academic-related outcomes (classroom behavior, cognitive function and academic achievement), specifically among primary school-aged children. A secondary aim is to examine the effect of these interventions on children's physical activity levels.

\section{Methods \\ Definitions}

While there are no set definitions for classroom-based physical activity, the following definitions are provided in order to maintain consistency and clarity throughout the remainder of this systematic review.

Classroom-based physical activity: physical activity carried out during regular class time, and can occur either inside or outside the classroom (e.g. hallway, playground), and is distinct from school recess/lunch break times. Classroom-based physical activity can take three forms:

- Active breaks: short bouts of physical activity performed as a break from academic instruction [24]. 
- Curriculum-focussed active breaks: short bouts of physical activity that include curriculum content $[25,26]$.

- Physically active lessons: the integration of physical activity into lessons in key learning areas other than physical education (e.g. mathematics) [27, 28].

Academic-related outcomes: overarching term to encompass factors associated with academic performance at school. These can be grouped into three main categories:

- Classroom behaviour: Observed behaviours that may promote or interfere with learning in the classroom, including on-task behaviour [29] (e.g. concentrating on tasks assigned by the teacher), and off-task behaviour (e.g. not concentrating on tasks assigned by the teacher).

- Cognitive function: Mental process (e.g. executive function) that may influence academic performance [29].

- Academic achievement: A child's performance on school-related tasks; often reported via classroom grades, national standardised tests or progress monitoring tools [29], as well as self-reported perceived academic competence [30].

\section{Registration and protocol}

This study followed the Preferred Reporting Items for Systematic Reviews and Meta-Analyses (PRISMA) recommendations for systematic review reporting, and was registered with the International Prospective Register of Systematic Reviews (PROSPERO) (record \#CRD42016027294).

\section{Search strategy}

Studies were identified through a systematic search of four electronic databases (PubMed, ERIC, SPORTDiscus and PsycINFO), first conducted in January 2016, and updated in January 2017 by one author (AW). The search strategy consisted of four elements (see Table 1). The search was limited to peer-reviewed articles published in English in all available years. 'Grey' literature, including the reference lists from the websites of two organisations ("Active Academics" and "Active Living Research") involved in children's physical activity research were also searched.

\section{Inclusion criteria}

A predetermined set of inclusion criteria were used to select papers for this systematic review. Each study had to meet the following criteria:

\section{Intervention study design;}

2. Investigated associations between classroom-based physical activity and at least one academic-related outcome. Interventions involving strategies in addition to classroom-based physical activity were excluded (to enable the effects of classroom-based physical activity to be isolated);

3. Study population included primary school-aged children (5-12 years);

4. Presented original data;

5. Did not focus specifically on special populations (e.g. overweight children).

\section{Study selection}

The search yielded 7729 citations from electronic database records, and 17 from 'grey' literature (Fig. 1). After removing duplicates $(n=500)$, the titles and/or abstracts of 7246 unique publications were screened by one author (AW). A total of 101 publications were identified as potentially relevant according to the inclusion criteria. Full texts of 98 of these 101 articles were obtained and reviewed independently by two authors to determine eligibility (AW, KB). Two full texts were conference abstracts only, and one full-text was unable to be retrieved despite extensive librarian-assisted enquiries and emails directly to the contact author. Of the 98 full-text articles, a total of 59 were excluded as not meeting inclusion criteria. Disagreements between the two reviewers were resolved through discussion with all authors. Reference lists of included articles were also examined, however no additional studies were identified. Thirty-nine unique citations satisfied the eligibility criteria and were included in this systematic review.

\section{Data extraction}

Paper characteristics including country of study, study design, participant characteristics, intervention characteristics, academic-related outcome measures, physical activity measures, and results were extracted by one author (AW). Interventions were then categorised as active break, curriculum focussed active break, or physically active lesson intervention.

\section{Methodological quality}

Two authors (AW, KB) independently assessed the methodological quality of the included studies using the Effective Public Health Practice Project (EPHPP) tool [31]. This six-component rating scale for interventions assesses (1) selection bias; (2) study design; (3) confounders; (4) blinding; (5) data collection methods; and (6) withdrawals and drop outs. Each component was rated on a three-point scale as either strong, moderate or weak using the tool's defined criteria. Based on these ratings, an overall methodological quality score was given; either strong (no weak component ratings); 


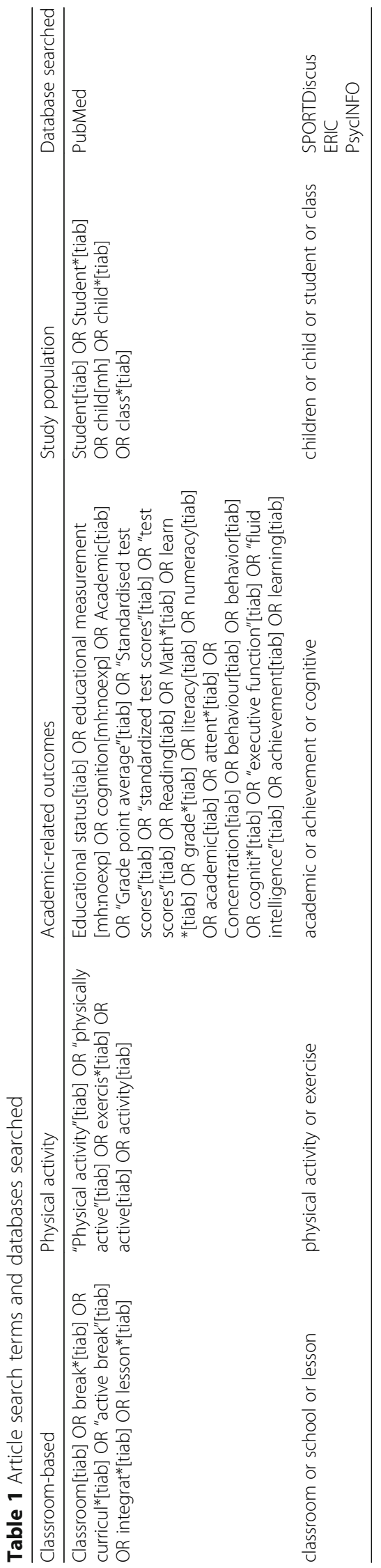




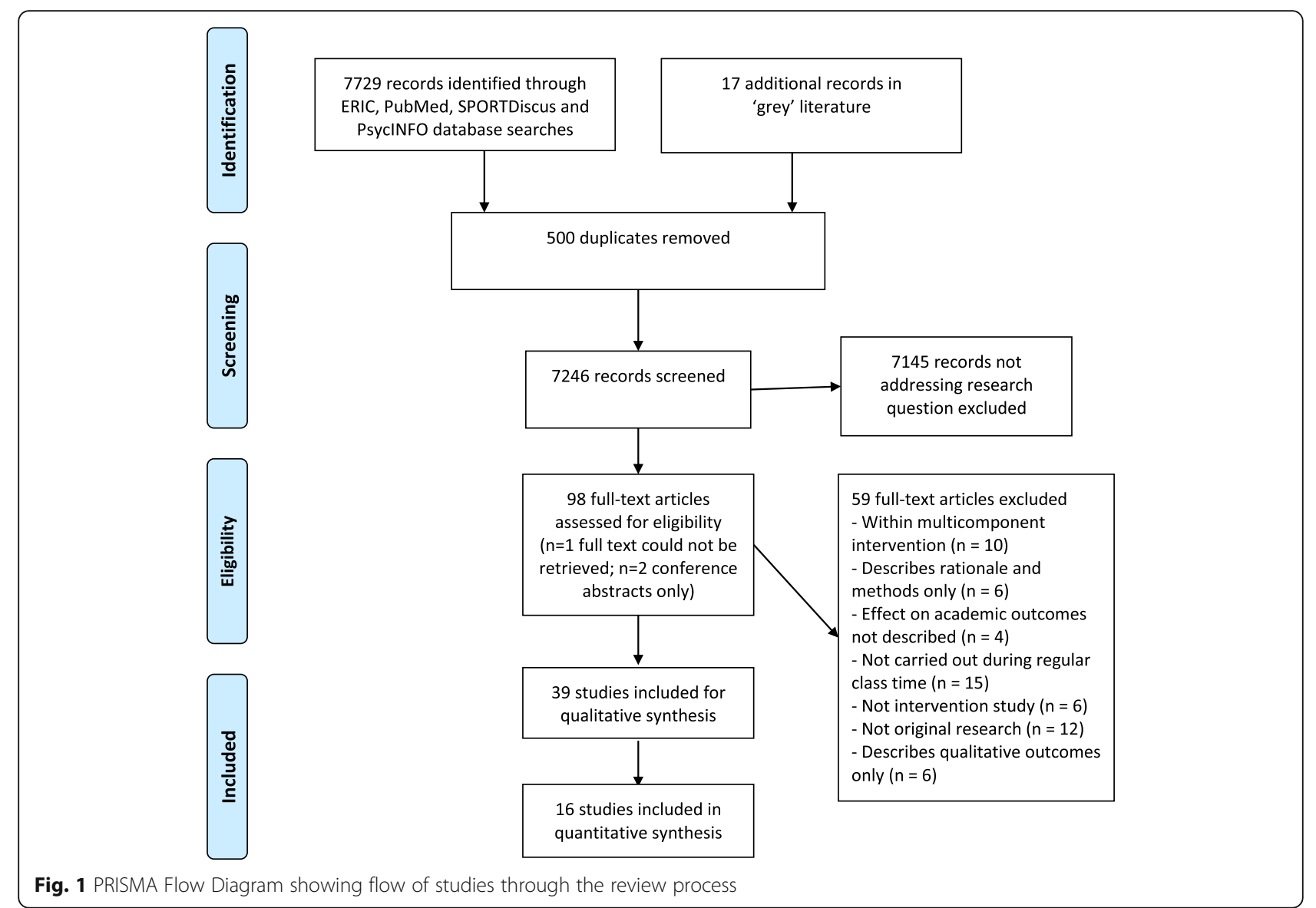

moderate (one weak component rating); or weak (more than one weak component rating), following the tool's accompanying instructions. Where disagreements existed, deliberation occurred until a consensus was reached.

\section{Meta-analyses}

Meta-analyses were conducted where there were at least three studies investigating the same broad outcome, i.e. classroom behaviour, cognitive function, or academic achievement. Due to heterogeneity across study designs, for inclusion studies were required to have a separate comparison group (i.e. RCT or quasi experimental with control group). Studies that used a within subject or cross over study design were therefore excluded from meta-analysis.

To avoid duplication of studies under a single outcome, where studies reported intervention effects on multiple measures for an outcome (this happened only for cognitive functions) [32, 33] a decision was made to include outcomes relating to executive functions, over memory. Executive functions, inhibition in particular, have been shown to be consistently related to academic achievement [34] and therefore were considered salient to teachers. Thus, where inhibition and memory were reported, only inhibition was included in the meta-analysis; where executive functions and short term memory were reported, only executive functions were included in the meta-analysis. Typically higher scores were reflective of better academic-related outcomes. Where lower scores reflected better academic-related outcomes these scores were reversed.

As academic achievement tools varied widely in quality, only studies using national standardised tests or progress monitoring tools were included in the metaanalyses. Further, intervention effects on mathematics were used when studies reported multiple subject assessments, as math was the most commonly reported outcome. Of the 39 studies included in this systematic review, 16 were included in meta-analyses. Reasons for exclusion were: insufficient data for calculating effect sizes and authors did not respond to email requests for additional data $(n=6)$, using a within subject or crossover study design $(n=9)$, not including a separate comparison group $(n=2)$, insufficient studies investigating 
an outcome $(n=4)$, or only reporting results separately for subgroups (e.g. BMI categories) $(n=2)$.

\section{Analysis}

Meta-analyses were conducted using Review Manager 5.3. The wide variation in interventions and academic-related outcomes employed in the different studies warranted use of a random effects model. Effect sizes (standardised mean difference) were computed as the difference between treatment and control means.

\section{Results}

Of the 39 studies identified, 19 examined the effect of active breaks $[24,26,35-51]$, seven examined curriculum-focussed active breaks [25, 52-57], and thirteen examined physically active lessons $[27,28,32,33$, 58-66] on academic-related outcomes. The majority of studies $(n=27)$ were published in or after 2014 [24, 26, $32,33,36,39-41,43,46-51,57,65,66]$, and none before 2006. Most $(n=18)$ were conducted in the USA $[25,36,39,40,42,44,45,51-55,57-60,64,65]$, seven in the Netherlands [32, 41, 49, 50,61, 62, 66], four in Australia [27, 28, 46, 47], three in Canada [24, 35, 43], two in Scotland [37, 38], and one each in South Africa [48], UK [63], Greece [56] Denmark [33], and Switzerland [26]. Sample sizes ranged from 14 [60] to over 4500 participants [45], with sample sizes $<300$ in the majority of studies $(n=28)[24-28,33,35,39-41$, $43,44,46-51,53,55-57,59-64]$. Intervention periods spanned from single lessons $[49,55,59,65]$ to 3 year duration [58], with most lasting no longer than nine weeks $(n=23)[24-28,33,37-41,43-46,48,50,52$, $55-57,59,63]$. Study information is presented in Table 2 (active breaks), Table 3 (curriculum focused active breaks) and Table 4 (physically active lessons).

\section{Intervention content}

There was considerable variation across studies in intervention content. While most (12 out of 19) active break interventions featured basic aerobic movements that students could be performed in their classroom (e.g. jumping jacks), and required no set-up or equipment $[24,35-40,42,43,45,50,51]$, others were performed outside the classroom (e.g. sports field) [26, 41, 46-48], and/or required additional equipment (e.g. markers, skipping ropes, balls, exercise bands, dance videos, or specialised stacking cups) [41, 44, 46, 49]. One study utilised both cognitively engaging active breaks (i.e. physical activity combined with cognitive demand) and active breaks to explore separate and combined effects of physical activity and cognitive engagement on cognitive function [26]. The target frequency, duration and physical activity intensity of the breaks varied, ranging from $4 \mathrm{~min}$ of vigorous-intensity physical activity weekly [24, 43] to 20 min of moderate intensity physical activity done twice per day [49].

There was more consistency in content across curriculum-focussed active breaks, compared with the active breaks without curriculum content. All curriculum-focussed active breaks featured physical activity integrated into a combination of key learning areas, including mathematics, language, science and/or social studies, and aimed to reinforce previously taught lesson content $[25,52-57]$. Further, most (5 out of 7) required daily participation in 10 to $20 \mathrm{~min}$ of physical activity $[19,52-54,57]$. When specified, participation was required at a moderate-[56] or moderate-to vigorous-physical activity intensity [55], but intensity was not specified in the majority (5 out of 7 ) of these studies $[25,52-54,57]$.

While curriculum-focussed active breaks aimed to reinforce previously taught lesson content, physically active lessons were used to teach new lesson content [27, 28, 32, 33, 58-62, 64-66]. These lessons predominately incorporated physical activity into mathematics and/or language lessons, but some also incorporated science and/or social studies $[27,28,32,33,58-62$, 64-66]. Lessons ranged in duration from 30 to 60 min $[27,28,32,33,60-64,66]$ with most (8 out of 13) requiring participation three times per week $[27,28,32,33,61,62,64,66]$. Other physically active lessons were described as single lessons as part of pilot interventions $[59,63,65]$, or stipulated physical activity time per week, rather than number of lessons per week [58].

\section{Intervention fidelity}

Intervention fidelity was reported in twelve studies. For the three active break interventions delivered by teachers, various measures of fidelity were used, however, no study clearly reported compliance with implementing active breaks daily or the number of active break sessions conducted. Active break interventions delivered by research staff reported high fidelity, showing most children achieved the required physical activity intensity [39-41], or at least $50 \%$ of each intervention session was spent at the required intensity $[46,47]$.

For physically active lesson interventions, teacher reports showed they delivered lessons either as intended [27] or for at least $50 \%$ of the required minutes per week [58]. Similar to active break studies, when delivered by research staff, at least $60 \%$ of intervention lessons were spent at the required physical activity intensity [61, 62]. No curriculum focussed active break study reported fidelity. 


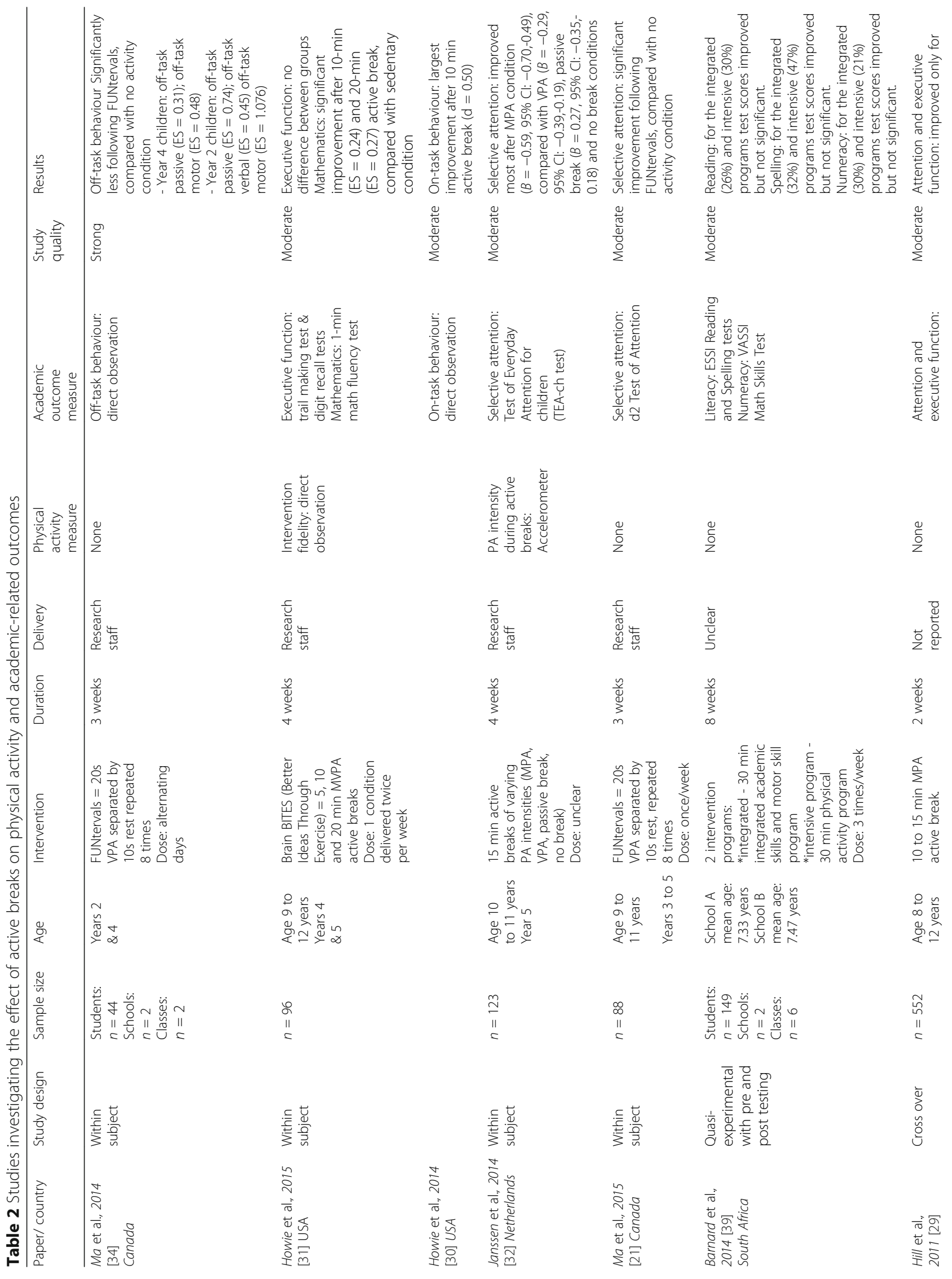




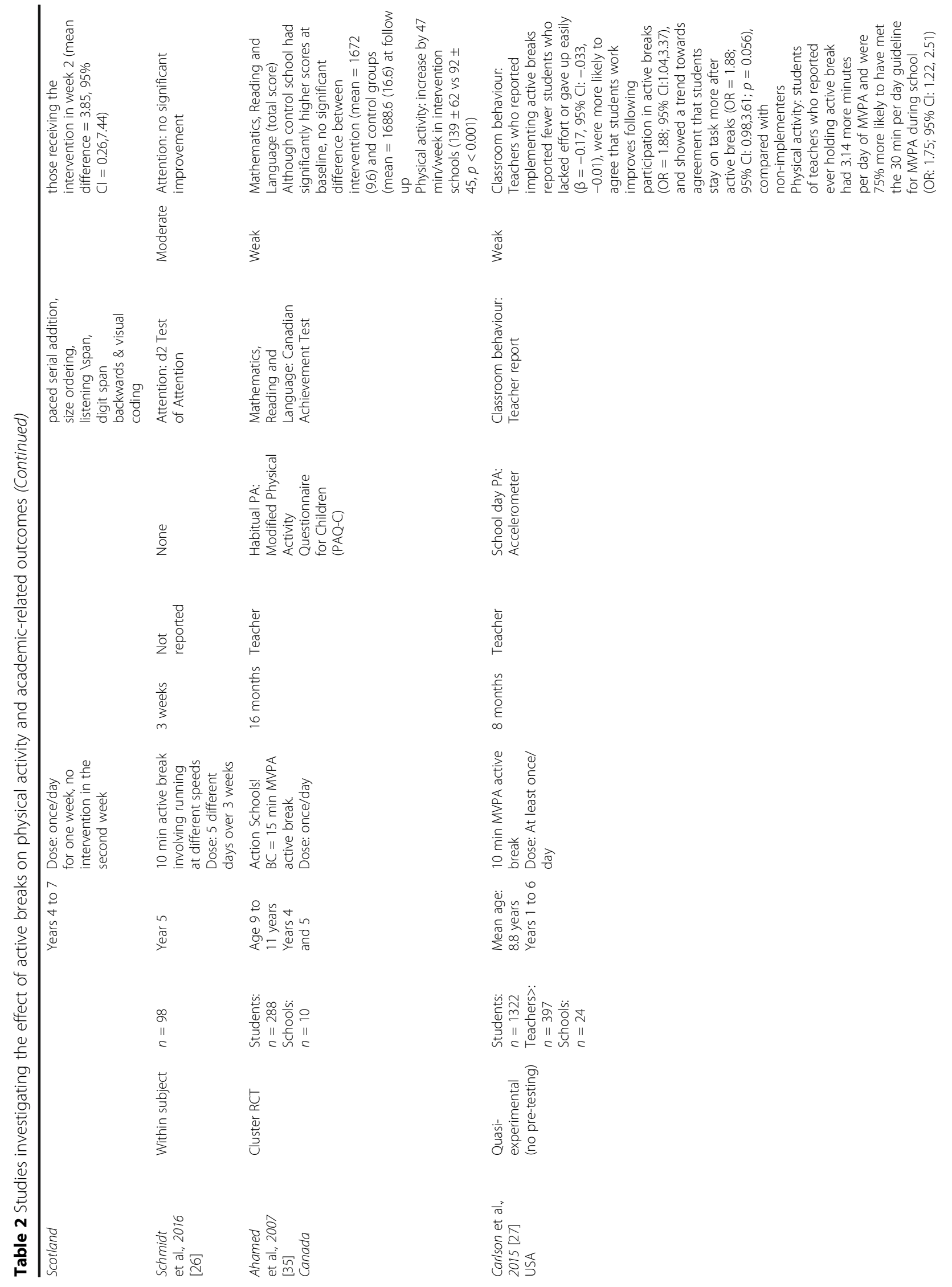




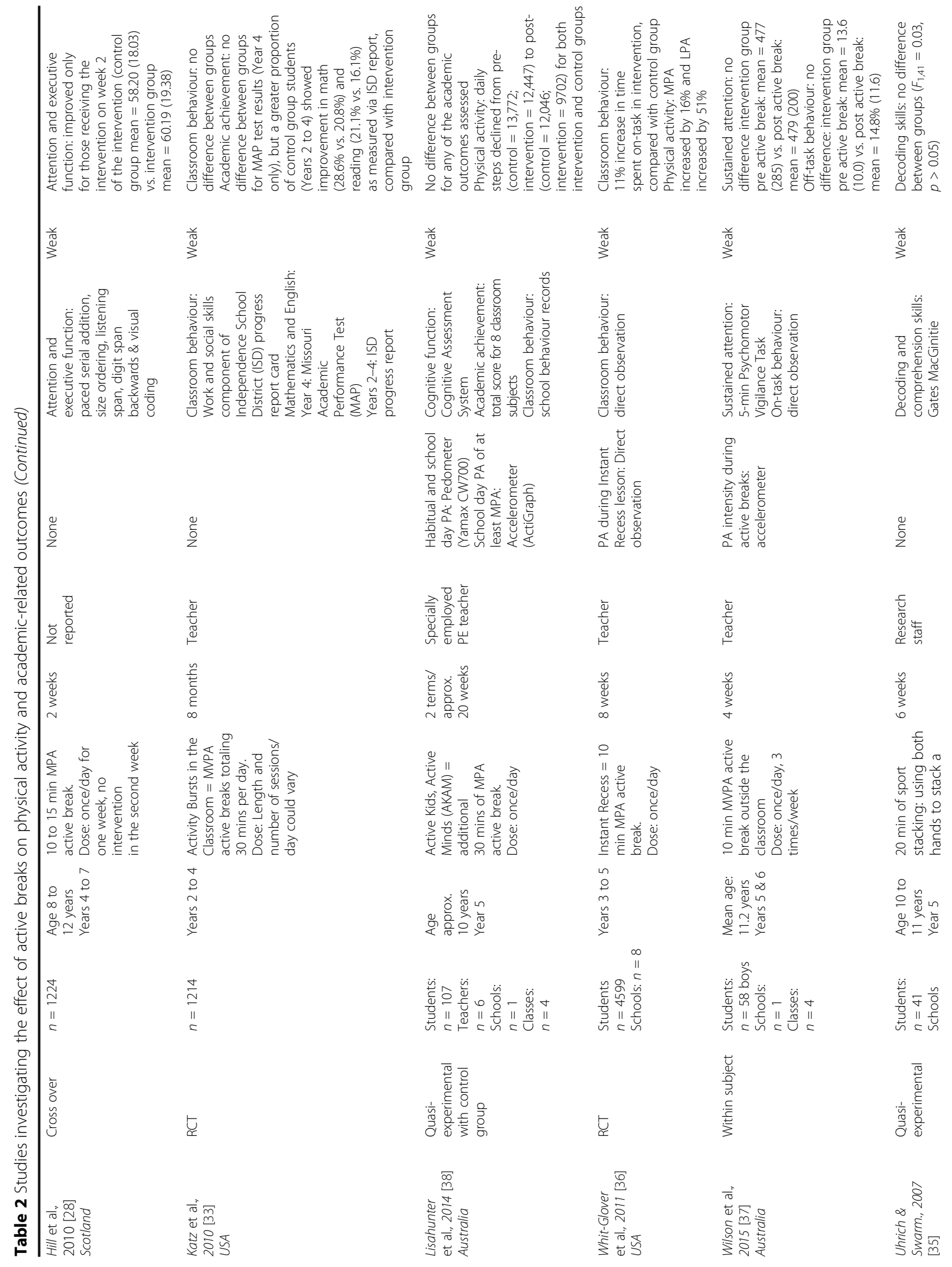




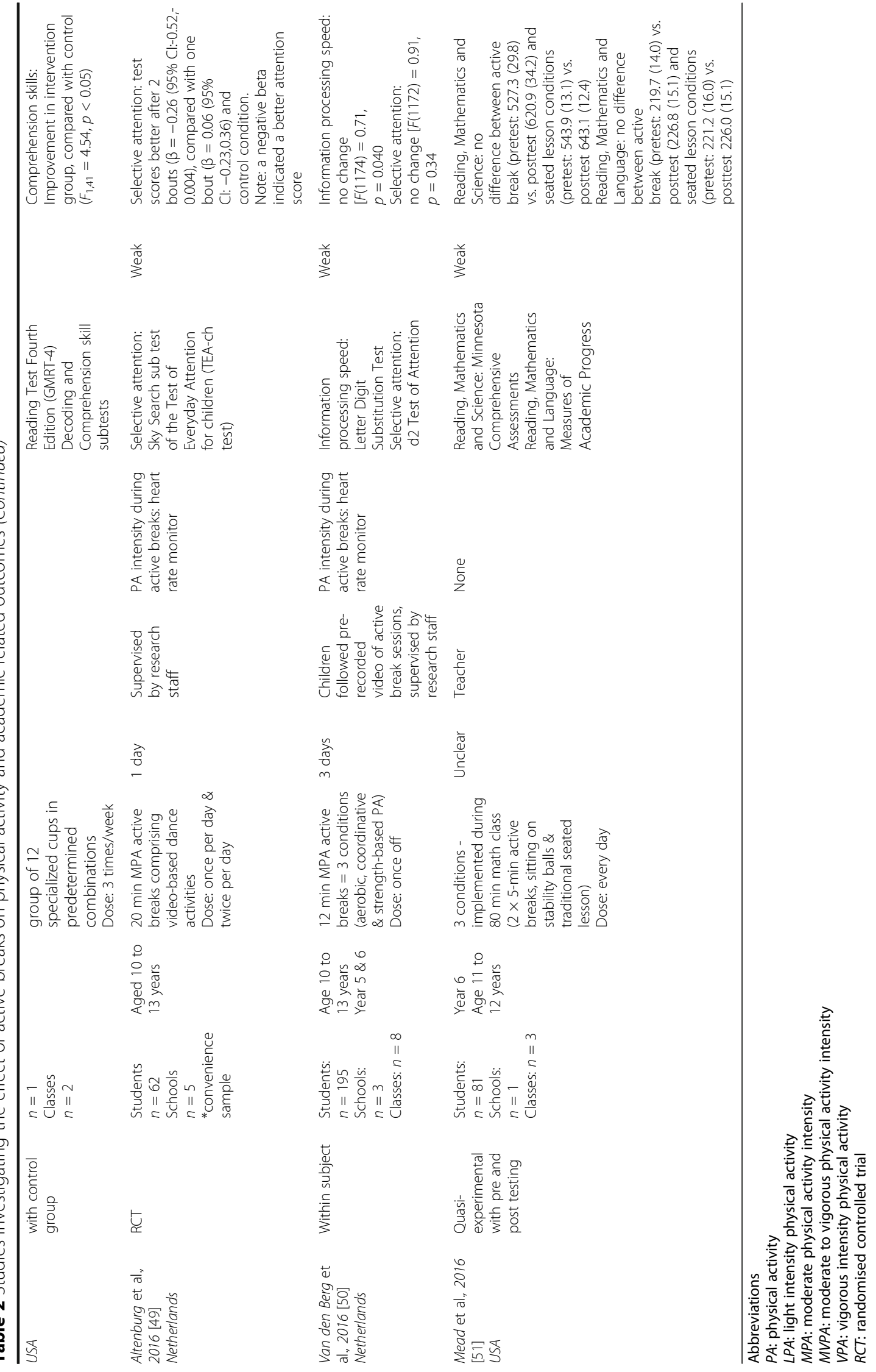




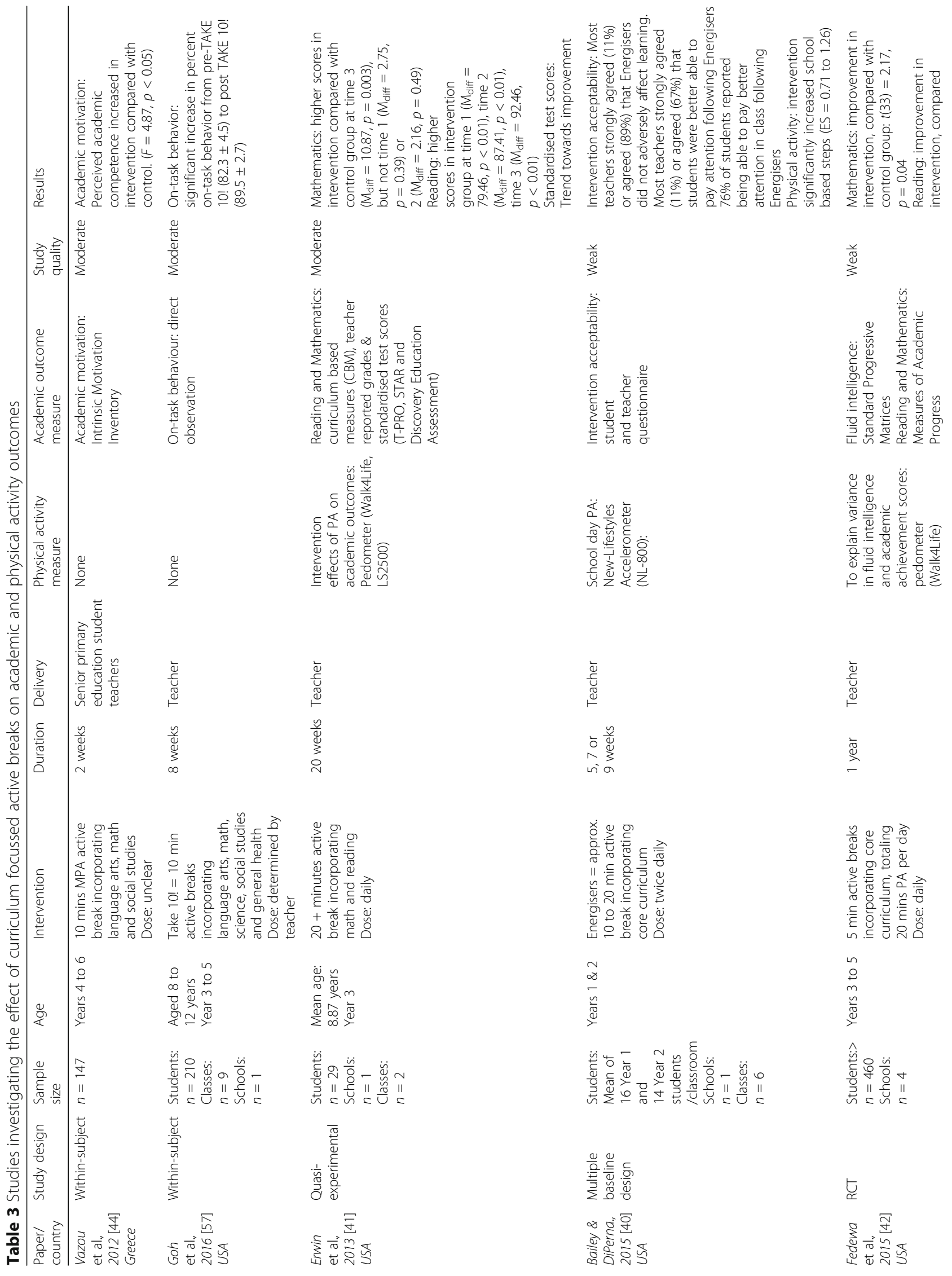




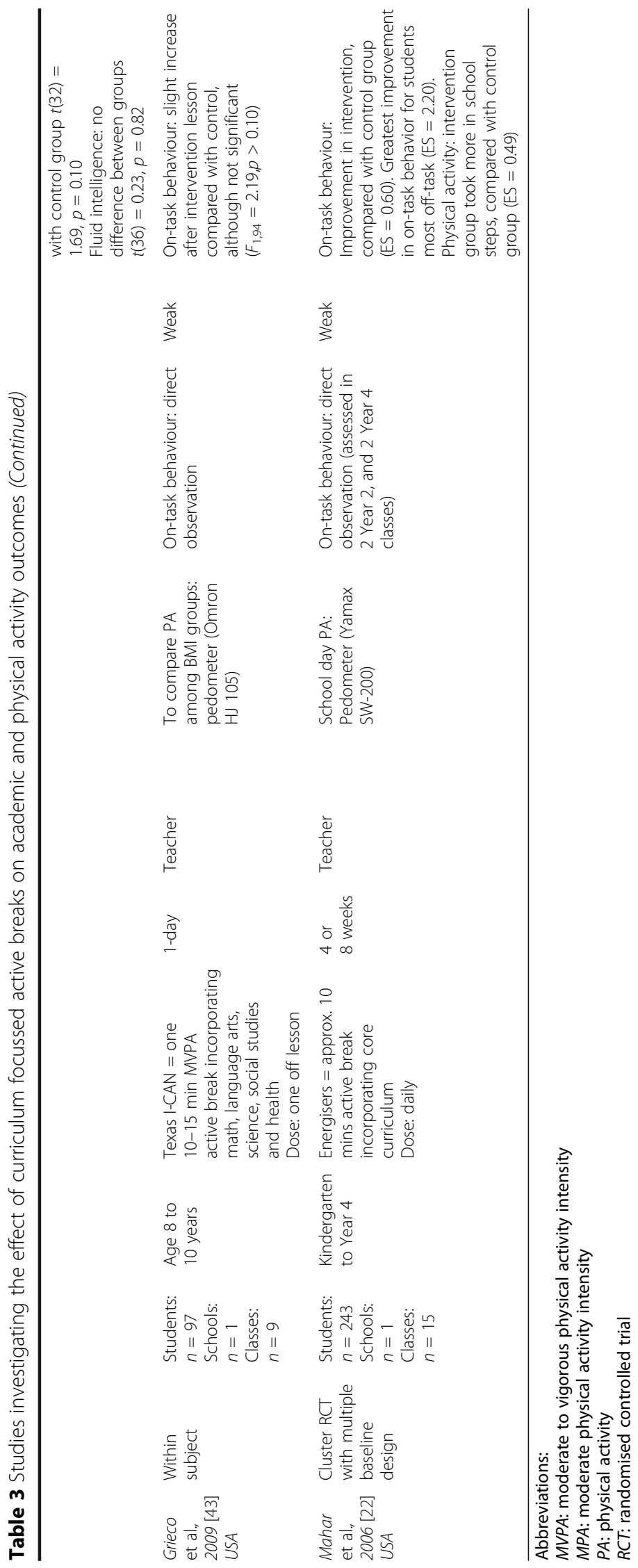




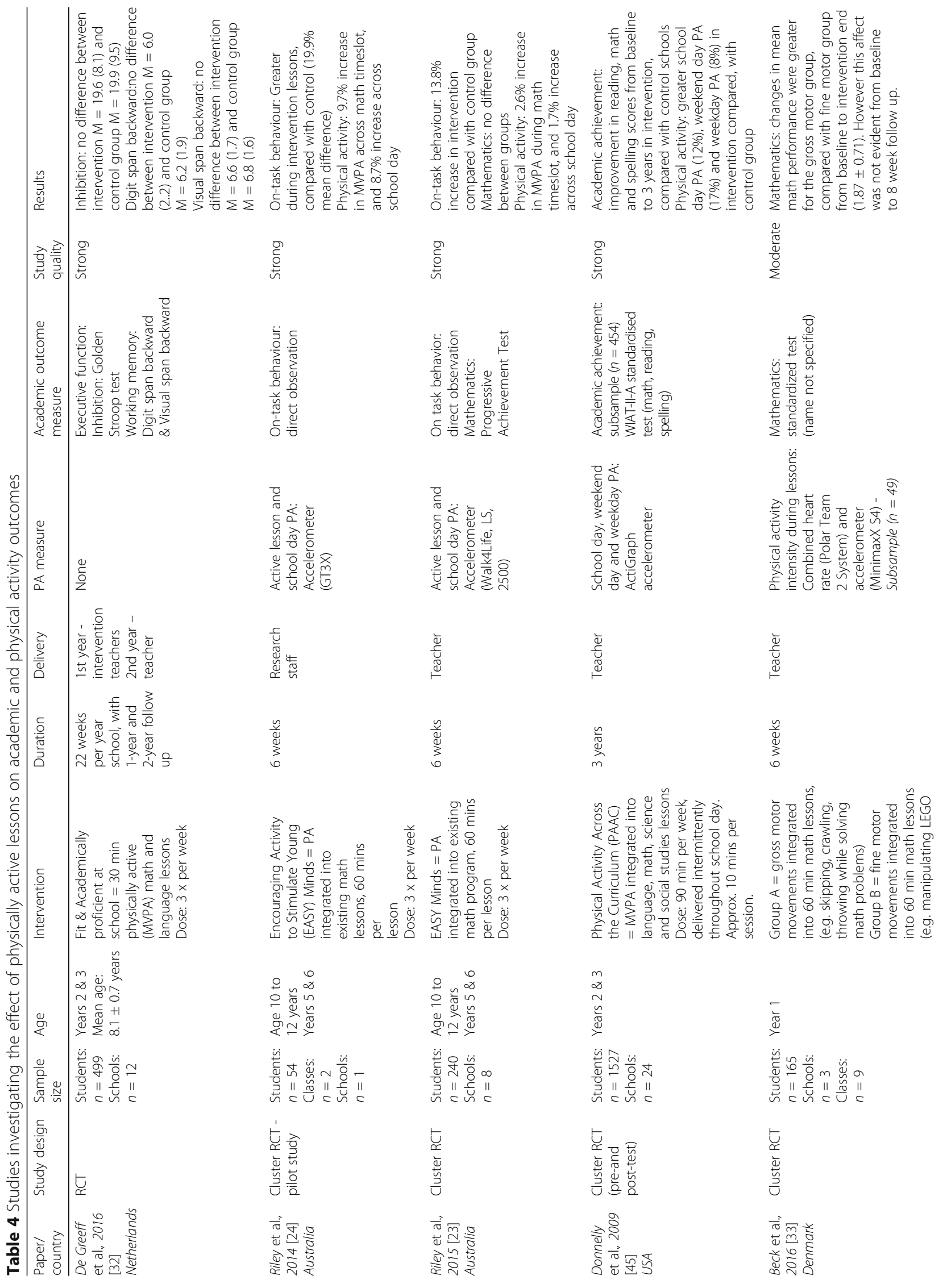




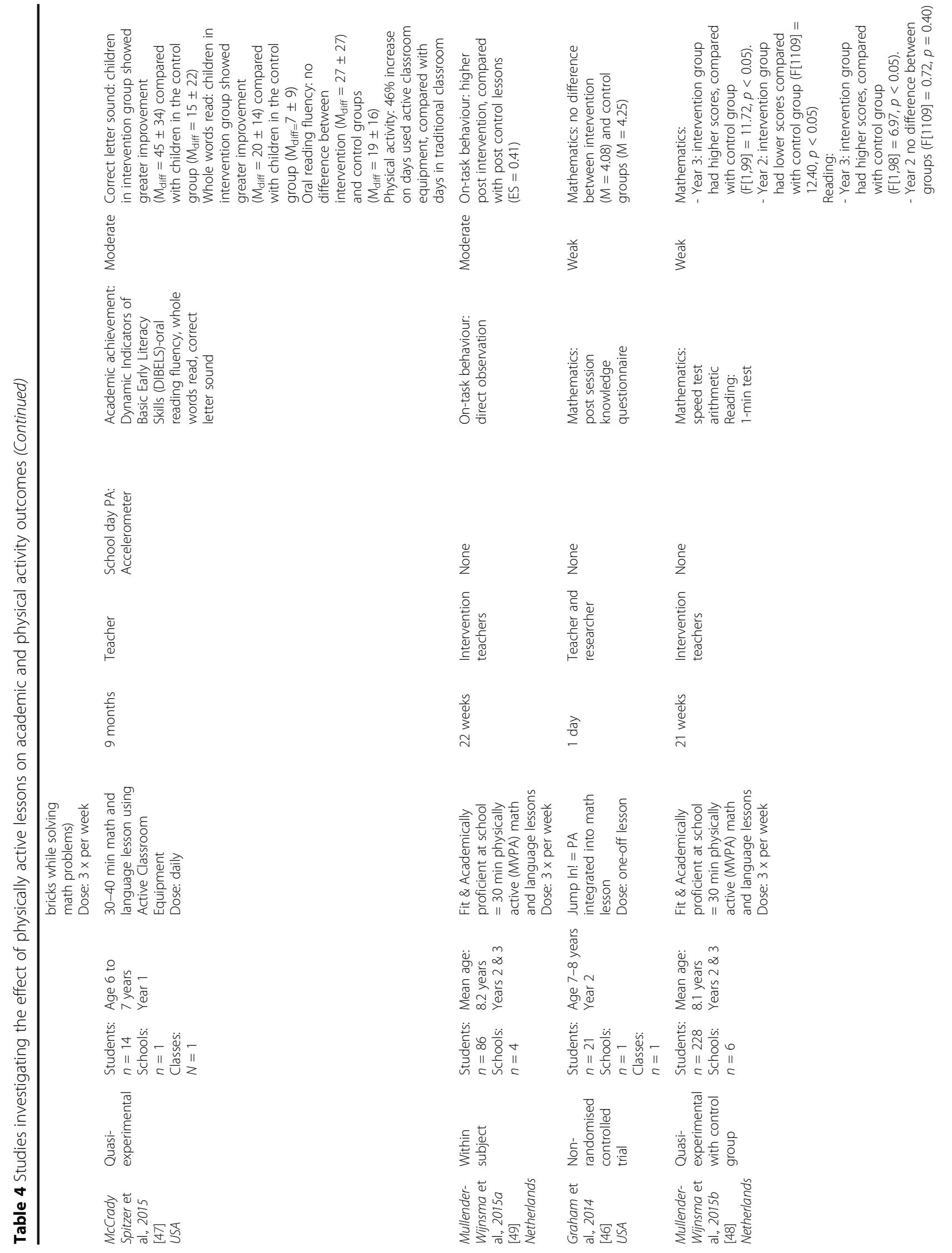




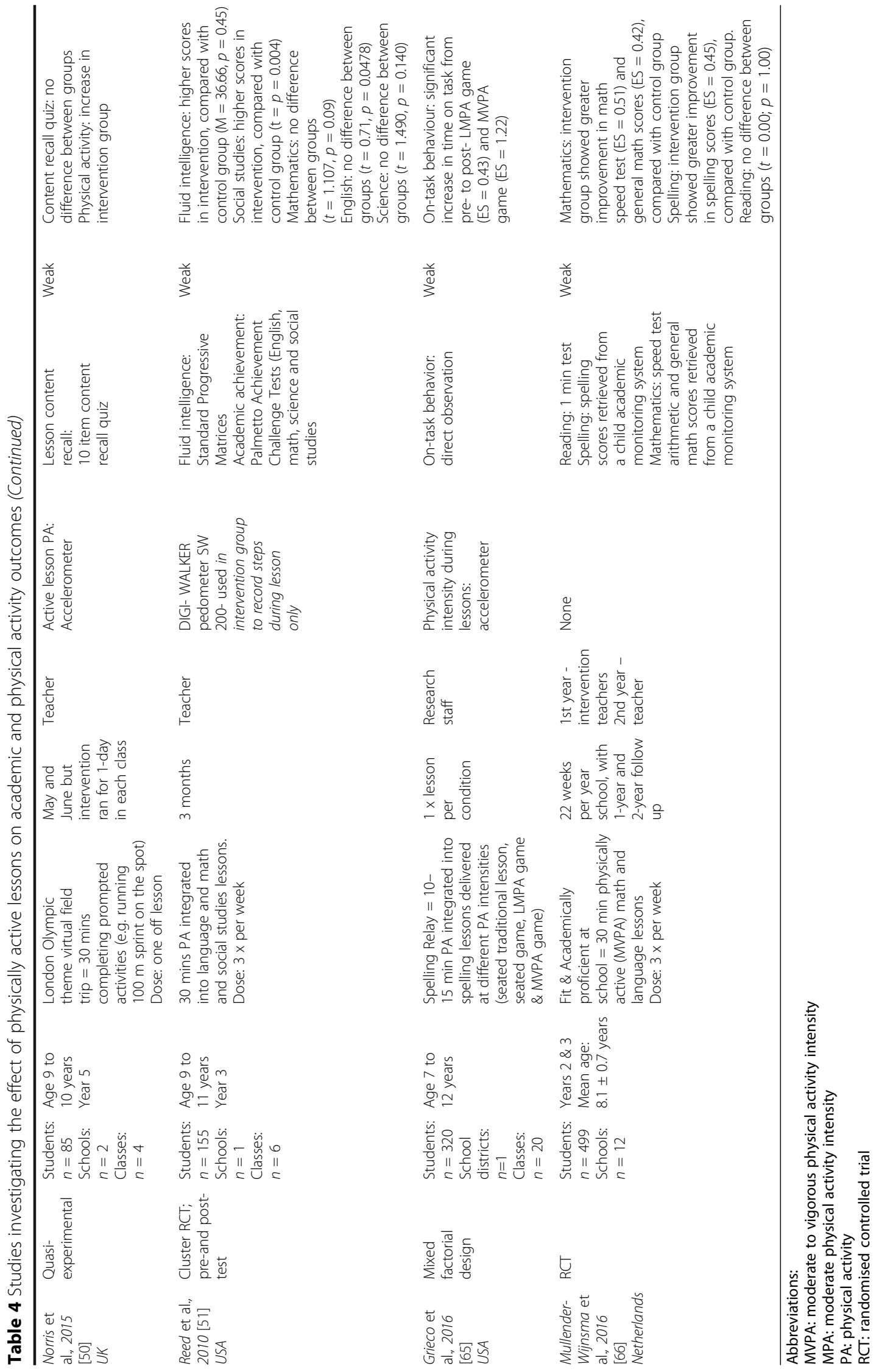




\section{Methodological quality}

Of the 39 identified studies, most (36 out of 39 ) received a moderate $[24,26,33,38-41,48,53,55-57,60,62]$, or weak quality rating score $[25,27,28,35-37,42,44-47$, $49-52,54,59,61,63-66]$. Three received a strong quality rating score $[32,43,58]$. Low to moderate quality score ratings were mostly attributable to not reporting or controlling for relevant demographic confounders, not reporting blinding of participants and researchers, and not reporting participant attrition. Further, for many studies, authors did not report the rate of participant or school participation. See Appendix A for further detail on quality assessment of included studies.

\section{Academic-related outcomes: Classroom behaviour}

Studies assessed the effect of participation in these programs on academic-related outcomes both immediately following participation in a session (acute) and after a longer exposure (chronic; e.g. pre- and post- intervention periods spanning up to 8 months). Regardless of type of classroom-based physical activity, the majority of studies (10 out of 12) showed participation in these programs had an acute effect on improving on-task classroom behaviour $[25,27,28,39,52,57,62,65]$ and reducing off-task behaviour [36, 43] However, evidence in the few studies with longer term follow-up (2 out of 2 studies) suggest that this improvement may dissipate over time, with no difference between groups when chronic intervention effects on reported behaviour incidents were assessed $[42,47]$. Due to few studies investigating chronic effects of classroom-based physical activity on on-task and off task classroom behaviour $(<5)$ it was not possible to separate acute and chronic effects in the meta-analysis. Results from the 4 included studies show classroom-based physical activity had a positive effect on improving on-task behaviour and reducing off-task behaviour (standardised mean difference $=0.60$ (95\% CI: 0.20,1.00)) (see Fig. 2).

\section{Academic-related outcomes: Cognitive function}

Studies also assessed acute and chronic effects of classroom-based physical activity on a range of cognitive functions [24, 32, 37, 38, 40, 41, 46, 47, 49, 50, 54, 64].
Results showed active breaks had an acute positive effect on selective attention (3 out of 4 studies) [24, 41, 49]. No acute effect was reported for sustained attention [46], information processing [50] or focussed attention, processing speed and accuracy [26], and no chronic effect was reported for planning, attention, simultaneous or successive cognitive processes [47] or executive function [32]. Acute intervention effects on executive function were inconsistent, with no difference between groups reported in one study [40], while another reported improvements in executive function but only for those receiving the intervention in the second week of delivery [37, 38]. Results were also inconsistent for chronic intervention effects on fluid intelligence, with one study reporting a significant improvement after 3 months [64], while another reported no difference between groups after 1-year [54]. Due to few studies reporting chronic effects of participation $(<5)$ results for acute and chronic studies were combined in the metaanalysis (5 studies). Results from the meta-analysis indicate classroom-based physical activity had no effect on cognitive function (standardised mean difference $=0.33$ (95\% CI: -0.11,0.77) (see Fig. 3).

\section{Academic-related outcomes: Academic achievement}

Studies assessed intervention effects on academic achievement using a range of academic assessment tools, including standardised tests, progress monitoring tools, grades and content recall quizzes. Reported effects on academic achievement varied by intervention duration and the type of assessment tool used. Interventions of shorter duration tended to show improvement in academic achievement if a progress monitoring tool was used, but not if a national standardised test was used. Seven out of 8 studies using a progress monitoring tool reported significant improvement in academic achievement following intervention periods ranging from 4 weeks to 1-year [40, 44, 53, $54,60,61,66]$. In contrast, most (4 out of 7) studies indicated no difference between groups following intervention periods less than 1-year when national standardised tests were used as the outcome measure $[27,42,64,66]$. However, standardised test scores

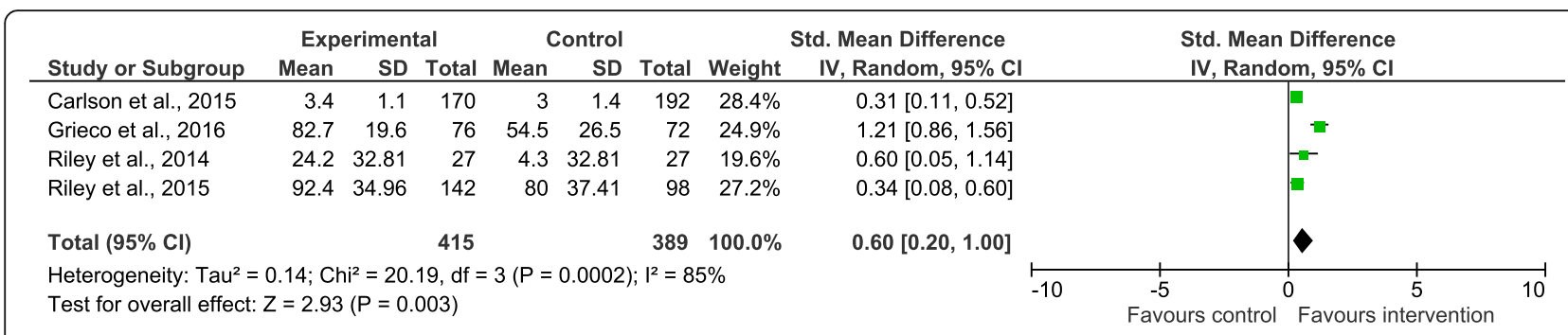

Fig. 2 Forrest plot of the effect of classroom-based physical activity on classroom behaviour 


\begin{tabular}{|c|c|c|c|c|c|c|c|c|c|c|c|c|}
\hline \multirow[b]{2}{*}{ Study or Subgroup } & \multicolumn{3}{|c|}{ Experimental } & \multicolumn{3}{|c|}{ Control } & \multicolumn{3}{|c|}{ Std. Mean Difference } & \multirow{2}{*}{\multicolumn{3}{|c|}{$\begin{array}{r}\text { Std. Mean Difference } \\
\text { IV, Random, } 95 \% \mathrm{Cl}\end{array}$}} \\
\hline & Mean & SD & Total & Mean & SD & Total & Weight & IV, Random, $95 \% \mathrm{CI}$ & & & & \\
\hline Altenburg et al., 2016 & 2.63 & 1.15 & 17 & 2.28 & 1 & 19 & $15.4 \%$ & $0.32[-0.34,0.98]$ & & \multicolumn{3}{|c|}{$f=$} \\
\hline Beck et al., 2016 & 97.7 & 0.8 & 51 & 96.6 & 0.8 & 49 & $19.1 \%$ & $1.36[0.93,1.80]$ & & \multicolumn{3}{|c|}{$-\pi$} \\
\hline de Greeff et al., 2016 & 19.6 & 8.1 & 176 & 19.9 & 9.5 & 167 & $22.2 \%$ & $-0.03[-0.25,0.18]$ & & \multicolumn{2}{|l|}{ t } & \\
\hline Fedewa et al., 2015 & 38.64 & 7.08 & 154 & 39.9 & 8.49 & 293 & $22.4 \%$ & $-0.16[-0.35,0.04]$ & & & & \\
\hline Reed et al., 2010 & 38.6 & 6.13 & 80 & 36.66 & 6.4 & 75 & $20.9 \%$ & $0.31[-0.01,0.63]$ & & \multicolumn{3}{|c|}{$=$} \\
\hline Total $(95 \% \mathrm{Cl})$ & & & 478 & & & 603 & $100.0 \%$ & $0.33[-0.11,0.77]$ & & \\
\hline \multicolumn{9}{|c|}{$\begin{array}{l}\text { Heterogeneity: } \mathrm{Tau}^{2}=0.22 ; \mathrm{Chi}^{2}=42.40, \mathrm{df}=4(\mathrm{P}<0.00001) ; \mathrm{I}^{2}=91 \% \\
\text { Test for overall effect: } Z=1.47(P=0.14)\end{array}$} & -10 & $\begin{array}{cc}-5 & 0 \\
\text { Favours control }\end{array}$ & $\begin{array}{c}5 \\
\text { Favours intervention }\end{array}$ & 10 \\
\hline
\end{tabular}

significantly improved following a 1-year [51] and 3year physically active lesson intervention [58]. These results were confirmed in the meta-analysis. When progress monitoring tools were used (4 studies) as the outcome measure, academic-related outcomes generally showed improvement (standardised mean difference $=1.03(95 \%$ CI: $-0.22,1.84))$. However, when measured using a national standardised test (6 studies), academic-related outcomes generally showed no improvement (standardised mean difference $=-1.13$ (95\% CI: -0.72,0.46)) (see Fig. 4).

In addition to standardised tests and progress monitoring tools, a small number of studies (not included in the meta-analysis) measured academic achievement via grades, content recall quizzes and self-reported academic competence. Results were inconsistent. One study reported no difference between groups for grades across eight subjects (total score) following a 20-week active break program [47], Another reported a greater proportion of students in the control group showed improvement in grades for math and reading, compared with an active break intervention group [42]. Other studies assessed academic achievement via content recall quizzes and perceptions of academic competence, with no difference between groups in math and social studies scores following participation in single lessons lasting between 10 and $30 \mathrm{~min}[59,63]$. Another study reported self-reported perceptions of academic competence improved during physically active lessons [56].

\section{Dose response relationship}

Four studies aimed to explore the optimal dose of active break (i.e. amount of physical activity required to confer academic benefits) required to provide maximum effects on academic-related outcomes, by manipulating intensity [41], duration [39, 40], and frequency [49] of active break sessions. Howie and colleagues $[39,40]$ compared 5-, 10- and 20-min active breaks with a 10-min no break condition. Results

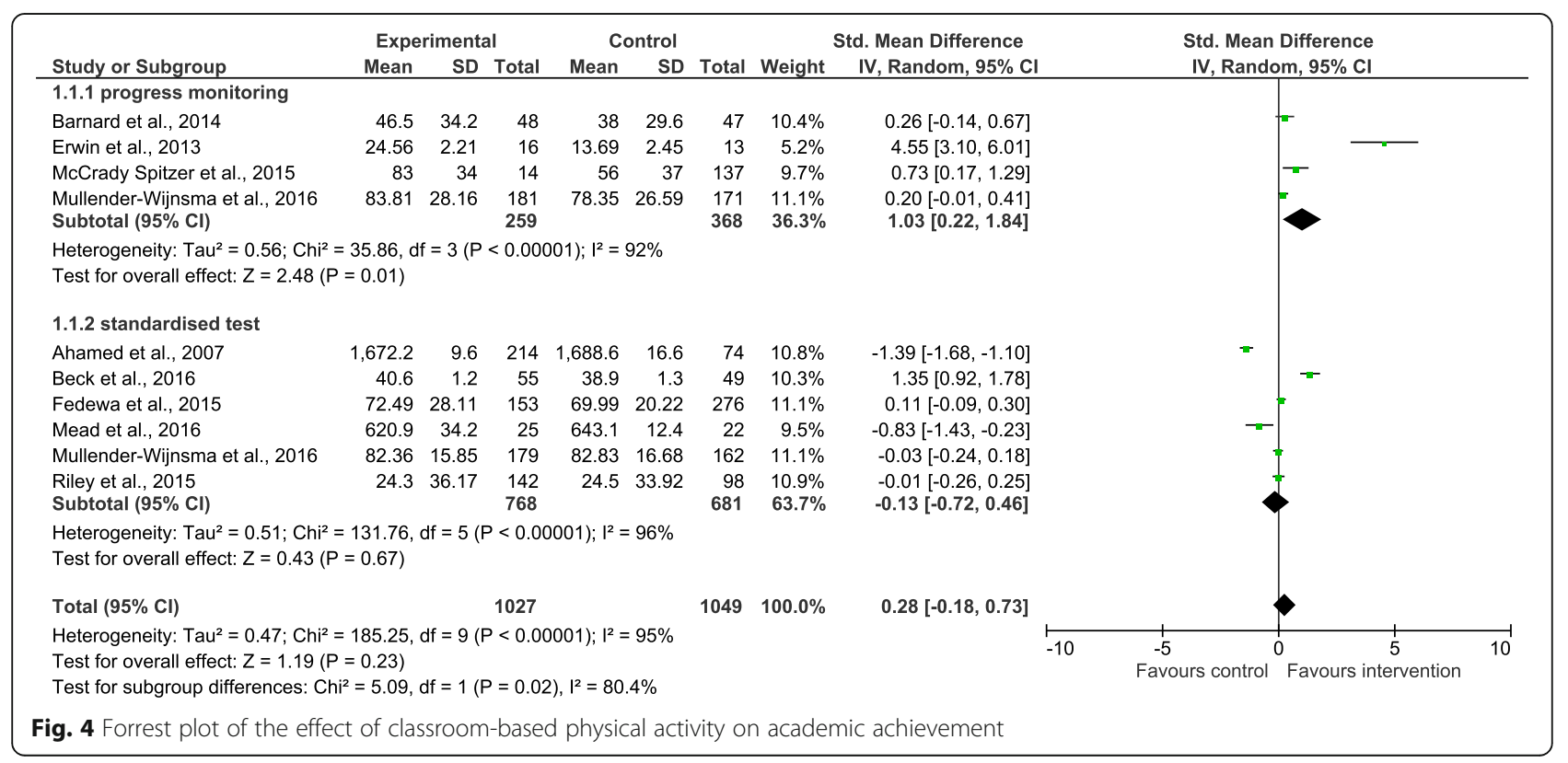


showed on-task classroom behaviour significantly improved after the 10-min active break condition [39] and math scores were highest after the 10-min $(\mathrm{ES}=0.24)$ and 20 -min $(\mathrm{ES}=0.27)$ active break conditions [40]. Janssen et al. [41] compared selective attention scores across $15 \mathrm{~min}$ of each of the following four conditions: no break (continued with school work), passive break (teacher read story), moderateintensity active break (jogging, passing, dribbling), and vigorous-intensity active break (running, jumping, skipping) [41]. Results showed that selective attention scores improved most after the moderate-intensity active break [41]. Altenburg and colleagues [49] compared acute effects of different frequencies (one per day vs. twice per day) of $20 \mathrm{~min}$ moderate-intensity active breaks. Results showed significantly better selective attention scores for children who received the twice per day frequency [49].

\section{Physical activity outcomes}

Eleven studies examined the effect of classroom-based physical activity interventions on children's physical activity levels using a range of measures, including questionnaire [35], direct observation [45], pedometer [25, $47,52]$, and accelerometer [27, 28, 36, 47, 58, 60, 63]. Across most (10 out of 11) classroom-based physical activity interventions, small increases in physical activity were reported [25, 27, 28, 35, 36, 45, 52, 58, 60, 63]. Across studies there was a $2 \%$ to $16 \%$ increase in moderate- to vigorous- intensity physical activity during intervention lessons, $[27,28,45,60,63]$, and $2 \%$ to $12 \%$ increase in school day moderate- to vigorous- intensity physical activity $[27,28,58]$. However, as shown in Fig. 5 results from 3 studies included in meta-analysis indicate classroom-based physical activity did not affect physical activity (standardised mean difference $=0.40(95 \%$ CI: $-0.15,0.95)$.

\section{Discussion}

A systematic search of the literature found 39 studies assessing the effect of classroom-based physical activity on academic-related outcomes, including classroom behaviour, cognitive function and academic achievement. In the majority of studies, academic-related outcomes improved following participation in classroom-based physical activity programs. These findings are generally consistent with earlier reviews finding that overall physical activity level was either positively associated, or was not associated with academic-related outcomes $[14,15,17]$. In addition, the interventions included in the current review generally resulted in more physical activity.

The finding that classroom-based physical activity improves on-task or reduces off-task classroom behaviour immediately following participation in intervention sessions is consistent with previous reviews of school-based physical activity. For example, systematic reviews of the effect of physical activity during the school break time on academic-related outcomes showed positive associations between participation in physical activity before class (e.g. during recess/snack time) and on-task classroom behaviour in subsequent lessons [17, 29]. Therefore, breaking up lesson time with physical activity offers a promising strategy to improve on-task behaviour. Further, physically active lessons may provide a strategy to engage students in lesson content, which may lead to improved on-task classroom behaviour. However, this assumption is purely speculative and further research is needed to confirm this. One study reported a nonsignificant increase in on-task classroom behaviour after intervention sessions, compared with control [55]. A possible reason for this finding may be that the sample size in that study $(n=97)$ may not have been large enough to detect a significant improvement. Few studies $(n=3)$ reported that classroombased physical activity had no effect on classroom behaviour. The majority of these studies (2 out of 3 ) reported that, while behaviour incidents and off-task behaviour increased in both the intervention and control groups, the increase was greater in the control group, compared with the intervention group [46, 47]. These findings may encourage teachers to consider implementing classroom-based physical activity programs by alleviating concerns about reducing on-task behaviour due to the disruption to the classroom routine [10].

While classroom-based physical activity showed relatively consistent positive associations with classroom behaviour, effects on cognitive function were inconsistent. A possible explanation for this finding may relate to the variability in the quality of measures used. Overall results showed studies that reported improvements in cognitive function used measures with moderate to high levels of reliability and validity $[67,68]$. In contrast, studies reporting no improvement in cognitive function mainly used measures with lower levels of reliability and validity [69-71]. It may be important for future studies to use tests of cognitive function with established validity and reliability.

A further possible explanation for inconsistent effects on cognitive function may relate to the level of cognitive engagement inherent in each type of classroom-based physical activity. It has been suggested that cognitively engaging physical activity (i.e. physical activity combined with cognitive demands) may enhance cognitive function to a greater degree than non-cognitively engaging physical activity (e.g. 


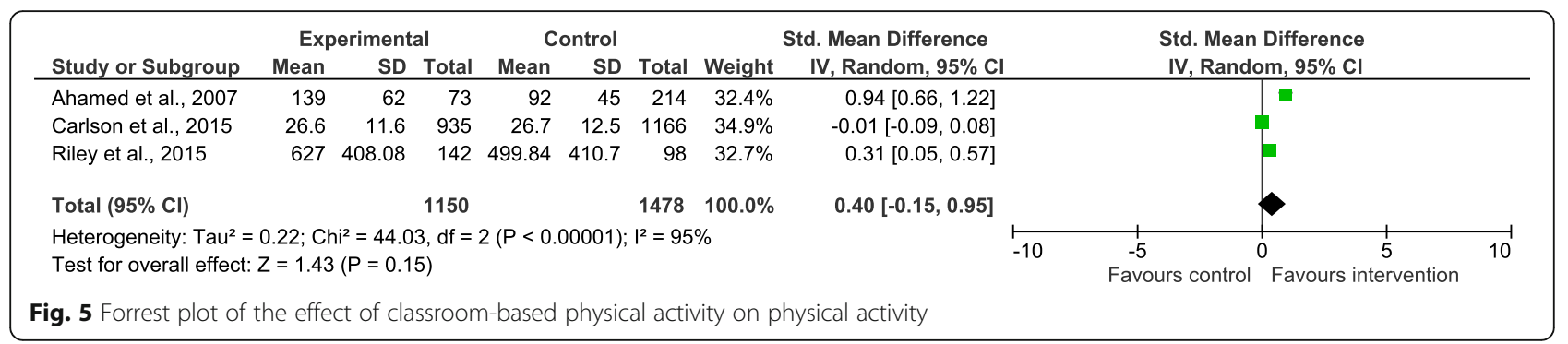

repetitive exercise) [72]. As curriculum-focused active breaks and physically active lessons can be considered cognitively engaging physical activity, it could be hypothesised that these types of classroom-based physical activity would lead to greater improvements in cognitive function, compared with active breaks that involve no cognitive content. While the majority of physically active lesson and curriculum focussed active break interventions ( 2 out of 3 studies) and only half of active break interventions (5 out of 10 studies) led to improvements in cognitive function, there were too few cognitively engaging interventions included in the review to draw a definitive conclusion. The one study that compared cognitively engaging and non-cognitively engaging active breaks, showed an impact on cognitive outcomes for the cognitively engaging breaks group only, lending support to this hypothesis [26]. Although not explicitly stated, many studies which do not purport to involve cognitively engaging physical activity involve some activities which are likely to confer cognitive engagement e.g. hopping sequences to music [37, 38], and coordinative exercises [50]. Some of these report positive and some null findings, yet it is difficult to ascertain the proportion of physical activity children were exposed to that was cognitively engaging. Future studies are encouraged to separate the effects of cognitively engaging and non-cognitively engaging physical activity on cognitive functions.

In addition to the cognitive test used, results may be dependent on the type of cognitive function assessed. For example, classroom-based physical activity appeared to have a particularly beneficial effect on selective attention [24, 41, 49], compared with other components of cognitive function, including sustained attention [46], fluid intelligence [54, 64], information processing speed [50], and executive function [32, 37, $38,40]$. However, a recent systematic review concluded that there is insufficient evidence to conclude what specific cognitive functions are most affected by physical activity [73]. Exercise-induced arousal may provide a further explanation for inconsistency in findings. This theory suggests that the heightened level of arousal during physical activity facilitates cognitive function and that this effect may be moderated by physical activity intensity [74]. However, while the majority of included studies reported a target physical activity intensity, few measured physical activity intensity during interventions precluding conclusions regarding the role of physical activity intensity on cognitive function. Thus, the favourable effect of physical activity on selective attention indicated in this review requires further research for confirmation. Nonetheless, should improvements in selective attention occur, such as the ability to ignore distractions this may be of particular interest to teachers and may provide motivation to incorporate physical activity into their classroom routine.

In addition to classroom behaviour and cognitive function, classroom-based physical activity may also have a positive effect on academic achievement. However, effects on academic achievement may be dependent on intervention duration and the type of assessment tool used to measure academic achievement. In the current review it appeared that interventions of shorter duration were more likely to show an improvement in academic achievement if a progress monitoring tool was used, rather than a national standardised test. This may be because curriculum-based measures are sensitive to small changes in academic achievement, and can be administered frequently (e.g. weekly) [75, 76], while standardised tests are usually designed to be administered less frequently (e.g. yearly), and are not sensitive to short-term progress. Therefore, progress monitoring tools may be a more suitable choice to determine intervention effects on academic achievement in the short-term. This finding has important implications for future research, indicating it may be important to consider intervention duration when selecting the measure of academic achievement. Therefore, future intervention studies may consider using a progress monitoring tool for intervention periods less than 1year, and standardised tests for intervention periods longer than 1-year if academic achievement is the outcome of interest. 
Other studies investigated the impact of different doses of classroom-based physical activity on academicrelated outcomes. However, results are based on few $(n=4)$ heterogeneous studies which considered a limited range of potential physical activity doses. Thus, further research is needed to be able to draw conclusions regarding the minimal dose of active break required to impact academic-related outcomes.

Several studies aimed to explore the effect of classroom-based physical activity on children's physical activity levels $[25,27,28,35,36,45,47,52,58$, $60,63]$. Results from the meta-analysis showed classroom-based physical activity did not affect physical activity levels. However, as only three of the 11 identified studies could be included in the metaanalysis these results should be interpreted with caution, and further research is warranted. Findings from the systematic review consistently revealed small increases in physical activity in children participating in the intervention, compared with students in the comparison group. These findings are in line with results from another review reporting positive associations between classroom-based physical activity interventions and children's physical activity levels [21]. While promising, it is possible compensation for this activity occurs outside of school. However, with limited information available, it is difficult to make strong conclusions on this. Further, it can be difficult to implement physical activity interventions in schools, often due to a lack of time associated with competing curriculum demands [77]. However, classroom-based physical activity is unique from other forms of school-based physical activity (e.g. Physical Education class and school sport) in that it does not compete for instructional time (physically active lessons and curriculumfocussed active breaks) or requires only minimal time commitment (active breaks). Thus, classroom-based physical activity may be a potentially appealing option for schools as it offers a time-efficient strategy to promote physical activity.

\section{Limitations}

The considerable variation between studies in study designs, intervention content and outcome assessment tools make it difficult to draw definitive conclusions, as evidenced by the small proportion of studies that could be included in meta-analyses. For studies that assessed intervention effects on physical activity, the majority compared physical activity levels during the classroom-based physical activity session, with a traditional seated lesson [27, 28, 45, 47], or assessed intervention effects on school day physical activity levels only $[25,27,28,36,52,60]$. Therefore, it is unclear if the increase in physical activity during these sessions is compensated for by a reduction in physical activity at other times of the day. However, as intervention effects on improving on-task, reducing offtask classroom behaviour and cognitive function appear to be primarily acute, this may not be a problem for these outcomes. In addition, few studies used an objective measure of physical activity intensity [27, $28,35,36,47,58,60,63]$. Thus, future studies using objective measures of physical activity are required to determine intervention effects on overall moderateto- vigorous-intensity physical activity, and to determine intervention fidelity (i.e. if the required physical activity intensity is met) within the sessions. Lastly, given that the majority of included studies reported significant improvements in academic-related outcomes, it is possible publication bias may have impacted the lack of published null associations.

\section{Conclusion}

Classroom-based physical activity interventions may provide a practical, low-cost, and effective strategy to increase academic-related outcomes, particularly acute positive effects on improving on-task and reducing offtask classroom behaviour and selective attention. Classroom-based physical activity could also have the potential to increase children's physical activity levels, however further research is needed to confirm this. Findings from this systematic review should be interpreted with caution given the high number of included studies of low methodological quality, suggesting there is room for improvement in classroom-based physical activity intervention study designs and reporting. This review has identified a number of areas for further research in order to increase understanding of the effect of classroom-based physical activity on academic and physical activity outcomes. These include the need for future studies to use objective measures of physical activity, and to consider intervention duration when selecting a measure of academic achievement. In addition, future studies should explore the effect of classroombased physical activity interventions on specific cognitive outcomes, as well as the impact of different types of physical activity (aerobic versus anaerobic versus resistance training and cognitively engaging vs. non-cognitively engaging physical activity) on academic-related outcomes. Further, it is not clear if improvements in academicrelated outcomes are a result of the physical activity or a result of the break from academic instruction, therefore future research is encouraged to add an attention control group. Lastly, it is recommended future studies use a standardized measure of cognitive function with established reliability and validity to be able to make comparisons across studies. 


\section{Appendix}

Table 5 Quality assessment of included studies

\begin{tabular}{|c|c|c|c|c|c|c|c|}
\hline Paper & Selection bias & Study design & Confounders & Blinding & $\begin{array}{l}\text { Data collection } \\
\text { methods }\end{array}$ & $\begin{array}{l}\text { Withdrawals } \\
\& \text { dropouts }\end{array}$ & Overall \\
\hline Goh et al., 2016 & moderate & moderate & strong & moderate & moderate & weak & MODERATE \\
\hline Beck et al., 2016 & moderate & strong & strong & moderate & weak & strong & MODERATE \\
\hline De Greeff et al., 2016 & moderate & strong & strong & moderate & strong & moderate & STRONG \\
\hline Altenburg et al., 2016 & weak & strong & strong & moderate & strong & weak & WEAK \\
\hline Mead et al., 2016 & weak & strong & weak & moderate & weak & weak & WEAK \\
\hline Mullender Wijnsma et al., 2016 & moderate & strong & weak & weak & strong & strong & WEAK \\
\hline Van den berg et al., 2016 & weak & strong & strong & moderate & moderate & weak & WEAK \\
\hline Grieco et al., 2016 & moderate & strong & weak & strong & moderate & weak & WEAK \\
\hline Carlson et al., 2015 & moderate & weak & weak & weak & strong & strong & WEAK \\
\hline Ma et al., 2015 & moderate & moderate & strong & moderate & strong & weak & MODERATE \\
\hline Ma et al., 2014 & moderate & moderate & strong & moderate & moderate & strong & STRONG \\
\hline Howie et al., 2014 & moderate & moderate & strong & moderate & strong & weak & MODERATE \\
\hline Howie et al., 2015 & moderate & moderate & strong & moderate & strong & weak & MODERATE \\
\hline Janssen et al., 2014 & weak & moderate & strong & moderate & strong & weak & MODERATE \\
\hline Wilson et al., 2015 & moderate & moderate & strong & moderate & weak & weak & WEAK \\
\hline Hill et al., 2011 & moderate & moderate & strong & strong & weak & strong & MODERATE \\
\hline Hill et al., 2010 & moderate & moderate & strong & strong & weak & weak & WEAK \\
\hline Ahamed et al., 2007 & moderate & strong & strong & moderate & weak & weak & WEAK \\
\hline Whitt-Glover et al., 2011 & moderate & strong & weak & moderate & weak & strong & WEAK \\
\hline Uhrich \& Swarm., 2007 & moderate & strong & weak & moderate & strong & weak & WEAK \\
\hline Katz et al., 2010 & moderate & strong & weak & moderate & weak & weak & WEAK \\
\hline Lisahunter et al., 2014 & weak & strong & weak & moderate & strong & weak & WEAK \\
\hline Bernard et al., 2014 & moderate & strong & weak & moderate & strong & strong & MODERATE \\
\hline Fedewa et al., 2015 & weak & strong & weak & moderate & strong & strong & WEAK \\
\hline Erwin et al., 2013 & moderate & strong & weak & moderate & strong & strong & MODERATE \\
\hline Grieco et al., 2009 & moderate & moderate & strong & moderate & moderate & weak & MODERATE \\
\hline Mahar et al., 2006 & moderate & strong & weak & moderate & moderate & weak & WEAK \\
\hline Bailey \& DiPerna., 2015 & moderate & moderate & strong & moderate & weak & weak & WEAK \\
\hline Vazou et al., 2012 & moderate & moderate & strong & moderate & strong & weak & MODERATE \\
\hline McCrady-Spitzer et al., 2015 & weak & moderate & strong & moderate & strong & strong & MODERATE \\
\hline Norris et al., 2015 & moderate & strong & strong & moderate & weak & weak & WEAK \\
\hline Mullender Wijnsma et al., 2015a & moderate & moderate & strong & moderate & moderate & weak & MODERATE \\
\hline Mullender Wijnsma et al., $2015 b$ & moderate & strong & weak & moderate & moderate & weak & WEAK \\
\hline Graham et al., 2014 & weak & strong and moderate & weak & moderate & weak & weak & WEAK \\
\hline Riley et al., 2014 & moderate & strong & weak & weak & weak & strong & WEAK \\
\hline Riley et al., 2015 & moderate & strong & strong & weak & weak & strong & WEAK \\
\hline Donnelly et al., 2009 & moderate & strong & strong & moderate & strong & strong & STRONG \\
\hline Reed et al., 2010 & weak & strong & weak & moderate & strong & weak & WEAK \\
\hline Schmidt et al., 2016 & moderate & strong & strong & moderate & strong & weak & MODERATE \\
\hline
\end{tabular}

Overall rating

Strong $=$ no weak ratings

Moderate $=1$ weak rating

Weak $=2$ or more weak ratings 


\section{Acknowledgements}

AW is a recipient of a Postgraduate Scholarship from Deakin University. AT is supported by a National Heart Foundation of Australia Future Leader Fellowship (Award 100046). KDH is supported by an Australian Research Council Future Fellowship (FT130100637) \& Honorary National Heart Foundation of Australia Future Leader Fellowship (100370).

\section{Funding}

N/A.

\section{Availability of data and materials}

N/A

\section{Authors' contributions}

AW conducted the database searches, screened titles, abstracts and full texts for eligibility criteria, performed methodological quality assessments and data extraction, and drafted the initial manuscript. KB reviewed full texts for eligibility criteria, and performed methodological quality assessments. $\mathrm{KDH}, \mathrm{HB}$, and $\mathrm{AT}$ contributed to interpretation of the data, and made contributions to multiple revisions of the manuscript. All authors read and approved the final manuscript.

\section{Authors' information (optional)}

AW is an experienced primary school teacher, and holds a Master of Public Health from the University of Adelaide.

\section{Ethics approval and consent to participate}

N/A

\section{Consent for publication}

N/A.

\section{Competing interests}

The authors declare they do not have any competing interests.

\section{Publisher's Note}

Springer Nature remains neutral with regard to jurisdictional claims in published maps and institutional affiliations.

\section{Received: 29 September 2016 Accepted: 14 August 2017}

\section{Published online: 25 August 2017}

\section{References}

1. Janssen I, LeBlanc AG. Systematic review of the health benefits of physical activity and fitness in school-aged children and youth. Int J Behav Nutr Phys Act. 2010;7

2. Okely $\mathrm{T}$, Salmon J, Vella S, Cliff D, Timperio A, Tremblay M, Trost S, Shilton $T$, Hinkley T, Ridgers N, Phillipson L, Hesketh K, Parrish A, Janssen X, Brown M, Emmel J, Marino N, A systematic review to update the Australian physical activity guidelines for children and young people., Report prepared for the Australian Government Department of Health, Editor, editors. Canberra. Australia: Commonwealth of Australia; 2012.

3. Active Healthy Kids Canada. Are we driving our kids to unhealthy habits? The 2013 Active Healthy Kids Canada Report Card on Physical Activity for Children and Youth. 201326 March 2015]; Available from: http://hepac.ca/ active-healthy-kids-2013/.

4. Australian Bureau of Statistics. Australian Health Survey: Physical Activity, 2011-12. 18 March 2015. 2013; Available from: http://www.abs.gov.au/ ausstats/abs@.nsf/Latestproducts/ 462FBA87B642FCA4CA257BAC0015F3CE?opendocument

5. Griffiths LJ, Cortina-Borja M, Sera F, Pouliou T, Geraci M, Rich C, Cole TJ, Law C, Joshi H, Ness AR, Jebb SA, Dezateux C. How active are our children? Findings from the millennium cohort study. BMJ Open. 2013;3(8):e002893.

6. Troiano RP, Berrigan D, Dodd KW, Masse LC, Tilert T, McDowell M. Physical activity in the United States measured by accelerometer. Med Sci Sports Exerc. 2008:40(1):181-8.

7. Sallis JF, McKenzie TL, Alcaraz JE, Kolody B, Faucette N, Hovell MF. The effects of a 2-year physical education program (SPARK) on physical activity and fitness in elementary school students. Sports, play and active recreation for kids. Am J Public Health. 1997;87(8):1328-34.
8. Ridgers ND, Stratton G, Fairclough SJ, Twisk JW. Long-term effects of a playground markings and physical structures on children's recess physical activity levels. Prev Med. 2007;44(5):393-7.

9. Fairclough SJ, Beighle A, Erwin H, Ridgers ND. School day segmented physical activity patterns of high and low active children. BMC Public Health. 2012;12:406.

10. McMullen J, Kulinna P, Cothran D. Physical activity opportunities during the school day: classroom Teachers' perceptions of using activity breaks in the classroom. J Teach Phys Educ. 2014;33(4):511-27.

11. Haapala E. Physical activity, academic performance and cognition in children and adolescents. A systematic review. Baltic Journal of Health \& Physical Activity. 2012;4(1):53-61.

12. Sibley BA, Etnier JL. The relationship between physical activity and cognition in children: a meta-analysis. Pediatr Exerc Sci. 2003;15:243-56.

13. Fedewa AL, Ahn S. The effects of physical activity and physical fitness on children's achievement and cognitive outcomes: a meta-analysis. Res $Q$ Exerc Sport. 2011;82(3):521-35.

14. Lees, C. and J. Hopkins, Effect of aerobic exercise on cognition, academic achievement, and psychosocial function in children: A systematic review of randomized control trials. Prev Chronic Dis, 2013. 10(10).

15. Singh A, Uijtdewilligen L, Twisk JWR, Van Mechelen W, Chinapaw MJM. Physical activity and performance at school: a systematic review of the literature including a methodological quality assessment. Arch Pediatr Adolesc Med. 2012;166(1):49-55.

16. Taras H. Physical activity and student performance at school. J Sch Health. 2005;75(6):214-8.

17. Trudeau F, Shephard RJ. Physical education, school physical activity, school sports and academic performance. Int J Behav Nutr Phys Act. 2008;5:10.

18. Bartholomew JB, Jowers EM. Physically active academic lessons in elementary children. Prev Med. 2011;52(Suppl 1):S51-4.

19. Mahar MT. Impact of short bouts of physical activity on attention-to-task in elementary school children. Prev Med. 2011;52(Suppl 1):S60-4.

20. Donnelly, J.E. and K. Lambourne, Classroom-based physical activity, cognition, and academic achievement. Preventive Medicine, 2011. 52(SUPPL.): p. S36-S42.

21. Norris E, Shelton N, Dunsmuir S, Duke-Williams O, Stamatakis E. Physically active lessons as physical activity and educational interventions: a systematic review of methods and results. Prev Med. 2015;72:116-25.

22. Owen KB, Parker PD, Van Zanden B, Macmillan F, Astell-Burt T, Lonsdale C. Physical activity and school engagement in youth: a systematic review and meta-analysis. Educ Psychol. 2016;51(2):129-45.

23. Erwin $\mathrm{H}$, Fedewa A, Beighle A, Ahn S. A quantitative review of physical activity, health, and learning outcomes associated with classroom-based physical activity interventions. J Appl Sch Psychol. 2012;28(1):14-36.

24. Ma JK, Le Mare L, Gurd BJ. Four minutes of in-class high-intensity interval activity improves selective attention in 9- to 11-year olds. Appl Physiol Nutr Metab. 2015;40(3):238-44.

25. Mahar MT, Murphy SK, Rowe DA, Golden J, Shields AT, Raedeke TD. Effects of a classroom-based program on physical activity and on-task behavior. Med Sci Sports Exerc. 2006;38(12):2086-94.

26. Schmidt, M., V. Benzing, and M. Kamer, Classroom-based physical activity breaks and Children's attention: cognitive engagement works! Frontiers in Psychology, 2016.

27. Riley, N., D.R. Lubans, K. Holmes, and P.J. Morgan, Findings from the EASY minds cluster randomized controlled trial: evaluation of a physical activity integration program for mathematics in primary schools. J Phys Act Health, 2015.

28. Riley N, Lubans DR, Morgan PJ, Young M. Outcomes and process evaluation of a programme integrating physical activity into the primary school mathematics curriculum: the EASY minds pilot randomised controlled trial. J Sci Med Sport. 2015;18(6):656-61.

29. Rasberry, C.N., S.M. Lee, L. Robin, B.A. Laris, L.A. Russell, K.K. Coyle, and A.J. Nihiser, The association between school-based physical activity, including physical education, and academic performance: A systematic review of the literature. Preventive Medicine, 2011. 52(SUPPL.): p. S10-S20.

30. Vazou S, Smiley-Oyen A. Moving and academic learning are not antagonists: acute effects on executive function and enjoyment. J Sport Exerc Psychol. 2014;36(5):474-85.

31. National Collaborating Centre for Methods and Tools. Quality Assessment Tool for Quantitative Studies. 2008; Available from: http://www.nccmt.ca/ resources/search/14. 
32. de Greeff JW, Hartman E, Mullender-Wijnsma MJ, Bosker RJ, Doolaard S, Visscher C. Long-term effects of physically active academic lessons on physical fitness and executive functions in primary school children. Health Educ Res. 2016:31(2):185-94.

33. Beck MM, Lind RR, Geertsen SS, Ritz C, Lundbye-Jensen J, Wienecke J. Motor-enriched learning activities can improve mathematical performance in preadolescent children. Front Hum Neurosci. 2016;10:645.

34. Best JR, Miller PH, Naglieri JA. Relations between executive function and academic achievement from ages 5 to 17 in a large, representative National Sample. Learn Individ Differ. 2011;21(4):327-36.

35. Ahamed Y, MacDonald H, Reed K, Naylor P-J, Liu-Ambrose T, McKay H. School-based physical activity does not compromise Children's academic performance. Med Sci Sports Exerc. 2007;39(2):371-6.

36. Carlson JA, Engelberg JK, Cain KL, Conway TL, Mignano AM, Bonilla EA, Geremia C, Sallis JF. Implementing classroom physical activity breaks: associations with student physical activity and classroom behavior. Prev Med. 2015;81:67-72.

37. Hill L, Williams JHG, Aucott L, Milne J, Thomson J, Greig J, Munro V, MonWilliams M. Exercising attention within the classroom. Developmental Medicine \& Child Neurology. 2010;52(10):929-34.

38. Hill LJB, Williams JHG, Aucott L, Thomson J. And M. Mon- Williams, How does exercise benefit performance on cognitive tests in primary-school pupils? Developmental Medicine \& Child Neurology. 2011;53(7):630-5.

39. Howie EK, Beets MW, Pate RR. Acute classroom exercise breaks improve ontask behavior in 4th and 5th grade students: a dose-response. Ment Health and Phys Act. 2014;7(2):65-71.

40. Howie EK, Schatz J, Pate RR. Acute effects of classroom exercise breaks on executive function and math performance: a dose-response study. Res Q Exerc Sport. 2015;86(3):217-24.

41. Janssen M, Chinapaw MJM, Rauh SP, Toussaint HM, van Mechelen W, Verhagen EALM. A short physical activity break from cognitive tasks increases selective attention in primary school children aged 10-11. Ment Health and Phys Act. 2014;7(3):129-34.

42. Katz DL, Cushman D, Reynolds J, Njike V, Treu JA, Walker J, Smith E, Katz C. Putting physical activity where it fits in the school day: preliminary results of the $A B C$ (activity bursts in the classroom) for fitness program. Prev Chronic Dis. 2010;7(4):A82.

43. Ma JK, Le Mare L, Gurd BJ. Classroom-based high-intensity interval activity improves off-task behaviour in primary school students. Appl Physiol Nutr Metab. 2014;39(12):1332-7.

44. Uhrich TA, Swalm RL. A pilot study of a possible effect from a motor task on reading performance. Percept Mot Skills. 2007;104(3 Pt 1):1035-41.

45. Whitt-Glover MC, Ham SA, Yancey AK. Instant recess(R): a practical tool for increasing physical activity during the school day. Prog Community Health Partnersh. 2011;5(3):289-97.

46. Wilson, A.N., T. Olds, K. Lushington, J. Petkov, and J. Dollman, The impact of 10-min activity breaks outside the classroom on male students' on-task behaviour and sustained attention: a randomised crossover design. Acta Paediatr, 2015

47. Lisahunter R, Abbott D, Macdonald J. Ziviani, and M. Cuskelly, Active kids active minds: a physical activity intervention to promote learning? AsiaPacific Journal of Health, Sport \& Physical Education. 2014;5(2):117-31.

48. Barnard M, Van Deventer KJ, Oswald MM. The role of active teaching programmes in academic skills enhancement of grade 2 learners in the Stellenbosch region. South African Journal for Research in Sport, Physical Education \& Recreation (SAJR SPER). 2014;36(3):1-14.

49. Altenburg TM, Chinapaw MJM, Singh AS. Effects of one versus two bouts of moderate intensity physical activity on selective attention during a school morning in Dutch primary schoolchildren: a randomized controlled trial. Journal of Science \& Medicine in Sport. 2016;19(10):820-4.

50. van den Berg V, Saliasi E, de Groot RH, Jolles J, Chinapaw MJ, Singh AS. Physical activity in the school setting: cognitive performance is not affected by three different types of acute exercise. Front Psychol. 2016;7:723.

51. Mead T, Scibora L, Gardner J, Dunn S. The impact of stability balls, activity breaks, and a sedentary classroom on standardized math scores. Physical Educator. 2016;73(3):433-49.

52. Bailey CG, DiPerna JC. Effects of classroom-based energizers on primary grade Students' physical activity levels. Physical Educator. 2015;72(3):480-95.

53. Erwin H, Fedewa A, Ahn S. Student academic performance outcomes of a classroom physical activity intervention: a pilot study. International Electronic Journal of Elementary Education. 2012;4(3):473-87.
54. Fedewa AL, Ahn S, Erwin H, Davis MC. A randomized controlled design investigating the effects of classroom-based physical activity on children's fluid intelligence and achievement. Sch Psychol Int. 2015;36(2):135-53.

55. Grieco LA, Jowers EM, Bartholomew JB. Physically active academic lessons and time on task: the moderating effect of body mass index. Med Sci Sports Exerc. 2009:41(10):1921-6.

56. Vazou S, Gavrilou P, Mamalaki E, Papanastasiou A, Sioumala N. Does integrating physical activity in the elementary school classroom influence academic motivation? International Journal of Sport \& Exercise Psychology. 2012;10(4):251-63.

57. Goh TL, Hannon J, Webster C, Podlog L, Newton M. Effects of a TAKE 10! Classroom-based physical activity intervention on third- to fifth-grade Children's on-task behavior. J Phys Act Health. 2016;13(7):712-8.

58. Donnelly JE, Greene JL, Gibson CA, Smith BK, Washburn RA, Sullivan DK, DuBose K, Mayo MS, Schmelzle KH, Ryan JJ, Jacobsen DJ, Williams SL. Physical activity across the curriculum (PAAC): a randomized controlled trial to promote physical activity and diminish overweight and obesity in elementary school children. Prev Med. 2009;49(4):336-41.

59. Graham DJ, Lucas-Thompson RG, O'Donnell MB. Jump in! An investigation of school physical activity climate, and a pilot study assessing the acceptability and feasibility of a novel tool to increase activity during learning. Front Public Health. 2014;2:58.

60. McCrady-Spitzer SK, Manohar CU, Koepp GA, Levine JA. Low-cost and scalable classroom equipment to promote physical activity and improve education. J Phys Act Health. 2015;12(9):1259-63.

61. Mullender-Wijnsma MJ, Hartman E, de Greeff JW, Bosker RJ, Doolaard S, Visscher C. Improving academic performance of school-age children by physical activity in the classroom: 1-year program evaluation. J Sch Health. 2015;85(6):365-71

62. Mullender-Wijnsma MJ, Hartman E, de Greeff JW, Bosker RJ, Doolaard S, Visscher C. Moderate-to-vigorous physically active academic lessons and academic engagement in children with and without a social disadvantage: a within subject experimental design. BMC Public Health. 2015;15:404.

63. Norris E, Shelton N, Dunsmuir S, Duke-Williams O, Stamatakis E. Virtual field trips as physically active lessons for children: a pilot study. BMC Public Health. 2015:15:366.

64. Reed JA, Einstein G, Hahn E, Hooker SP, Gross VP, Kravitz J. Examining the impact of integrating physical activity on fluid intelligence and academic performance in an elementary school setting: a preliminary investigation. J Phys Act Health. 2010;7(3):343-51.

65. Grieco LA. E.M. Jowers, V.L. Errisuriz, and J.B. Bartholomew, Physically active vs. sedentary academic lessons: A dose response study for elementary student time on task. Prev Med. 2016;89:98-103.

66. Mullender-Wijnsma MJ, Hartman E, de Greeff JW, Doolaard S, Bosker RJ, Visscher C. Physically active math and language lessons improve academic achievement: a cluster randomized controlled trial. Pediatrics. 2016;137(3): e20152743.

67. Brickenkamp R, Zillmer E. d2 Test of Attention, in d2 Test. Clark, Editors: P.L. Ackerman and $E_{;} 1998$.

68. Manly T, Nimmo-Smith I, Watson P, Anderson V, Turner A, Robertson $\mathbb{H}$. The differential assessment of children's attention: the test of everyday attention for children (TEA-Ch), normative sample and ADHD performance. Journal of Child Psychology and Psychiatry and Allied Disciplines. 2001;42(8):1065-81.

69. Neyens LGJ. and A.P. Aldenkamp. Stability of cognitive measures in children of average ability.

70. Nunnally, J.C., Psychometric theory. McGraw-Hill series in psychology. 1967: New York, McGraw-Hill [1967].

71. Roach GD, Dawson D, Lamond N. Can a shorter psychomotor vigilance task be used as a reasonable substitute for the ten-minute psychomotor vigilance task? Chronobiol Int. 2006;23(6):1379-87.

72. Best JR. Exergaming immediately enhances children's executive function. Dev Psychol. 2012;48(5):1501-10.

73. Lubans D, Richards J, Hillman C, Faulkner G, Beauchamp M, Nilsson M, Kelly P, Smith J, Raine L, Biddle S. Physical activity for cognitive and mental health in youth: a systematic review of mechanisms. Pediatrics. 2016;138(3):1642.

74. Lambourne, K. and P. Tomporowski, The effect of exercise-induced arousal on cognitive task performance: a meta-regression analysis. Brain Res, 2010. 1341(0): p. 12-24.

75. Madelaine A, Wheldall K. Towards a curriculum-based passage reading test for monitoring the performance of low-progress readers using standardised passages: a validity study. Educ Psychol. 1998;18(4):471-8. 
76. Madelaine A, Wheldall K. Further progress towards a standardised curriculum-based measure of reading: calibrating a new passage reading test against the new South Wales basic skills test. Educ Psychol. 2002;22(4):461-71.

77. Naylor P-J, Nettlefold L, Race D, Hoy C, Ashe MC, Wharf Higgins J, McKay HA. Implementation of school based physical activity interventions: a systematic review. Preventive Medicine: An International Journal Devoted to Practice and Theory. 2015;72:95-115.

Submit your next manuscript to BioMed Central and we will help you at every step:

- We accept pre-submission inquiries

- Our selector tool helps you to find the most relevant journal

- We provide round the clock customer support

- Convenient online submission

- Thorough peer review

- Inclusion in PubMed and all major indexing services

- Maximum visibility for your research

Submit your manuscript at www.biomedcentral.com/submit 